\title{
Effects of Electron Beam Irradiation on Elasticity of CFRTP (CF/PEEK)
}

\author{
Hiroaki Takei ${ }^{1, *}$, Michelle Salvia $^{2}$, Alain Vautrin $^{3}$, Akira Tonegawa $^{4}$ and Yoshitake Nishi ${ }^{1,2,3,4}$ \\ ${ }^{1}$ Graduate School of Engineering, Tokai University, Hiratsuka 259-1292, Japan \\ ${ }^{2}$ Ecole Centrale de Lyon, Ecully Cedex 69134, France \\ ${ }^{3}$ Department of Mechanical and Materials Engineering, Ecole Nationale Superieure des Mines de Saint-Etienne, \\ Saint-Étienne Cedex 2 42023, France \\ ${ }^{4}$ Graduate School of Science \& Technology, Tokai University, Hiratsuka 259-1292, Japan
}

\begin{abstract}
Homogeneous low voltage electron beam irradiation (HLEBI) improved the elasticity indicated by both flexural modulus $\left(E_{\mathrm{f}}\right)$ and the maximum slope value $\left((\mathrm{d} \sigma / \mathrm{d} \varepsilon)_{\max }\right)$ of the bending stress-strain curve of carbon fiber reinforced thermoplastic polyetheretherketone (CFRTP) composite sheets with $0.50 \mathrm{~mm}$ thickness, although the penetration depth estimated was from 0.14 to $0.21 \mathrm{~mm}$ on both side surfaces. HLEBI remarkably enhanced both $E_{\mathrm{f}}$ and $(\mathrm{d} \sigma / \mathrm{d} \varepsilon)_{\max }$. The $E_{\mathrm{f}}$ at middle cumulative probability $\left(P_{\mathrm{E}}\right)$ of 0.50 for CFRTP irradiated at $0.30 \mathrm{MGy}\left(\mathrm{kJg}^{-1}\right)$ was $3.3 \mathrm{GPa}$, which was $27 \%$ higher $(2.6 \mathrm{GPa})$ than for CFRTP before irradiation. Moreover, $(\mathrm{d} \sigma / \mathrm{d} \varepsilon)_{\max }$ at middle cumulative probability $\left(P_{\mathrm{E}}=0.50\right)$ was more than $4.9 \mathrm{GPa}$ for CFRTP irradiated at $0.30 \mathrm{MGy}$. The interfacial friction force, as well as the strengthening of both carbon fiber and polyetheretherketone probably contributed to the HLEBI effects to enhance both $E_{\mathrm{f}}$ and $(\mathrm{d} \sigma / \mathrm{d} \varepsilon)_{\max }$ in the CFRTP. [doi:10.2320/matertrans.MBW201005]
\end{abstract}

(Received October 22, 2010; Accepted February 1, 2011; Published March 30, 2011)

Keywords: carbon fiber reinforced polymers (CFRTP), polyetheretherketone, carbon fiber, electron beam irradiation, flexural modulus

\section{Introduction}

Carbon fiber reinforced polymers (CFRP), which are typical composite materials, have been applied as light structural materials with high strength. ${ }^{1,2)}$ Further strengthening has been always expected to develop high-speed mover machines with tiny energy consumption.

Electron beam irradiation greater than one $M e V$-class high voltage easily induces radiation damage, ${ }^{3)}$ whereas electron beam irradiation with extremely low voltage of less than $10 \mathrm{keV}$-class simply charges materials. While $0.10 \mathrm{MeV}$-class electron beam has been homogeneously irradiated at an optimum absorption dose, it is referred to as homogeneous low voltage electron beam irradiation (HLEBI). It often improves not only the fracture strain of polymer, ${ }^{4,5)}$ but also the mist resistance of transparent ceramics. ${ }^{6-8)}$ In addition, the irradiation has improved not only the bending fracture strain, ${ }^{9}$ but also the hardening modulus, tensile strength, and corresponding strain of carbon fiber. ${ }^{10)}$ To apply to highspeed mover transports, HLEBI also enhances the bending fracture stress, its strain and impact value of thermo-hardened CFRP. ${ }^{5,11)}$

Carbon fiber reinforced thermoplastic polymers (CFRTP) can be easily produced with high productivity, which is its industrial attractive point for mass production with various forming process. ${ }^{12)}$ However, weak adhesive force at interface between fibers and thermoplastic polymer matrix is a serious problem resulting in low strengthening of CFRTP.

HLEBI often enhances the deformation resistivity (elasticity) of polymer ${ }^{13)}$ and carbon fiber.9,10,14) In addition, it is also possible to enhance the interfacial strength induced by surface activation by charging, as well as compressive stresses at the interface by dangling bond formation in the polymer. Since the interfacial area of carbon fiber with

*Graduate Student, Tokai University

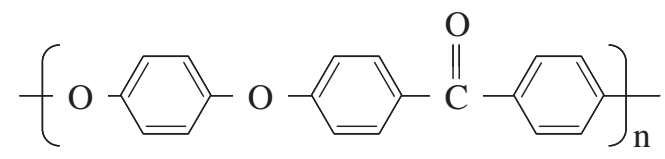

Fig. 1 Rational formula of polyetheretherketone (PEEK).

$6.0 \mu \mathrm{m}$ diameter is extremely large, it is possible that HLEBI enhances the friction force, resulting in strengthening the CFRTP. In order to enhance the interfacial friction force, HLEBI is probably effective for the interface in CFRTP.

Figure 1 illustrates the rational formula of polyetheretherketone (PEEK), which has high heat and corrosion resistance. ${ }^{15)}$ Thus, it is generally applied to interiors and upholsteries of the cabin and parts in airplanes and automobiles.

Radiation damage of PEEK matrix in CFRTP irradiated by electron beam with high voltage of $1.5 \mathrm{MeV}$ and high absorbed doses of $10 \mathrm{GGy}\left(10^{4} \mathrm{~J} \mathrm{~m}^{-1}\right)$ has been observed. ${ }^{16)}$ On the contrary, the mechanical properties of CFRTP $(\mathrm{CF} /$ PEEK) have been improved by $0.10 \mathrm{MeV}$ class-HLEBI without the radiation damage. The high impact value of CFRTP (CF/PEEK) has been obtained to clarify the effects of HLEBI. ${ }^{17)}$ Since elasticity is a typical basic mechanical property, the effect of HLEBI on elasticity has been expected for the design for practical articles. Therefore, the purpose of the present work is to investigate effects of HLEBI on flexural modulus and the maximum slope value $\left((\mathrm{d} \sigma / \mathrm{d} \varepsilon)_{\max }\right)$ of the bending stress-strain curve of CFRTP constructed of PEEK and carbon fiber.

\section{Experimental Procedure}

\subsection{CFRTP sample preparation}

The CFRTP sample, with a volume of $0.30 \mathrm{~cm}^{3}$, has been constructed with the bundle of carbon fiber (Diameter $=$ 
$6.0 \mu \mathrm{m}, \mathrm{T} 800 \mathrm{HB}$, Toray Industries, Inc.) and thermoplastic polymer (Polyetheretherketone; APTIV 2000-025, Victrex plc) matrix. Volume fractions of carbon fiber and polymer matrix were 61 and $39 \mathrm{vol} \%$, respectively. The composites were manufactured under $30 \mathrm{MPa} \mathrm{Ar}-\mathrm{H}_{2}$ gas atmosphere at $390^{\circ} \mathrm{C}$ for $1.0 \mathrm{~min}$. Since the bundle direction is the longitudinal direction, the high unidirectional strength can be expected.

\subsection{Bending test}

In order to evaluate the stiffness, the flexural modulus of the CFRTPs with and without HLEBI were measured using a testing methods for three-point bending test (IMADA Co., Ltd. DPU-50N/MX-500N/GA-10N) (see JIS K 70741998). ${ }^{18)}$ The CFRTP sample dimensions were: $60 \mathrm{~mm}$ length, $10 \mathrm{~mm}$ width and $0.50 \mathrm{~mm}$ thickness. Both bending stress $(\sigma)$ and bending strain $(\varepsilon)$ were expressed by the following equations. ${ }^{18)}$

$$
\begin{aligned}
& \sigma=(3 P L) /\left(2 b h^{2}\right) \\
& \varepsilon=(6 h d) / L^{2}
\end{aligned}
$$

Here, $\sigma, P, L, b, h, \varepsilon$, and $d$ were bending stress (MPa), load $(\mathrm{N})$, distance between supporting points $(20 \mathrm{~mm})$, sample width $(=10 \pm 0.20 \mathrm{~mm})$, sample thickness $(=0.50 \pm 0.15$ $\mathrm{mm}$ ), bending strain, and amount of deflection $(\mathrm{mm})$, respectively.

The flexural modulus $\left(E_{\mathrm{f}}\right.$ : GPa) was expressed by the following equation. ${ }^{18)}$

$$
E_{\mathrm{f}}=(1 / 4)\left\{L^{3} /\left(b h^{3}\right)\right\}(P / d)
$$

Here, $E_{\mathrm{f}}$ was flexural modulus $(\mathrm{GPa})$ and the maximum slope value $\left((\mathrm{d} \sigma / \mathrm{d} \varepsilon)_{\max }\right)$ was determined from the slope of stressstrain curves within elastic deformation of $\varepsilon= \pm 8.0 \times 10^{-4}$. The distance between supporting points was $20 \mathrm{~mm}$. The testing speed was $6.5 \mathrm{~mm} / \mathrm{min}$.

\subsection{Condition of EB-irradiation}

Sheet electron beam irradiation with low energy was homogeneously performed using an electron-curtain processor (Type CB175/15/180L, Energy Science Inc., Woburn, MA). ${ }^{6-11,13,14)}$ The specimen was machined from the sheet heat-treated for making composites and was homogeneously irradiated with the electron beam through a titanium thin film window attached to the vacuum chamber, $240 \mathrm{~mm}$ in diameter. Since HLEBI treatment was after forming interface between carbon fiber and PEEK matrix, improvement of adhesive force could be expected. A tungsten filament in a vacuum was used to generate the electron beam at a low energy (acceleration potential, $V$ : $\mathrm{MeV}$ ), of $0.17 \mathrm{MeV}$ and irradiating current density $\left(\mathrm{J}: \mathrm{Am}^{-2}\right)$ of $0.089 \mathrm{Am}^{-2}$. Although electron beam generation was done in a vacuum, the irradiated sample was kept under protective nitrogen at atmospheric pressure. The distance between sample and window was $35 \mathrm{~mm}$. To prevent oxidation, the samples were kept in a protective $1.0 \mathrm{~atm}$ of nitrogen gas with a residual concentration of oxygen below $0.030 \%$. The flow rate of nitrogen gas was $1.5 \mathrm{Ls}^{-1}$ at $0.10 \mathrm{MPa}$ of nitrogen gas pressure. Each absorbed dose $\left(0.043 \mathrm{MGy}\left(\mathrm{kJg}^{-1}\right)\right)$ was applied for only a short time $(0.23 \mathrm{~s})$ to avoid excessive heating of the sample; the temperature of the sample surface remained below $323 \mathrm{~K}$ just after irradiation. The sample in the aluminum plate holder $(0.15 \mathrm{~m} \times 0.15 \mathrm{~m})$ was transported on a conveyor at a speed of $10 \mathrm{~m} \cdot \mathrm{min}^{-1}$. The sheet electron beam irradiation was applied intermittently. Repeated irradiations to both side surfaces of samples were used to increase the total dose of irradiation. The interval between the end of one period of irradiation and the start of the next operation was $30 \mathrm{~s}$. When the irradiation current $(I: \mathrm{mA})$, the conveyor speed $\left(S: \mathrm{m} \mathrm{min}^{-1}\right)$ and number of irradiations $(N)$ were determined, the irradiated dose ( $D$ : MGy) was expressed by the following equation. ${ }^{19)}$

$$
D=0.216(I / S) N
$$

The absorbed dose was controlled by the integrated irradiation time in each of the samples. Here, absorbed dose was corrected by using FWT nylon dosimeter of RCD radiometer film (FWT-60-00: Far West Technology, Inc. 330-D South Kellogg Goleta, California 93117, USA) with irradiation reader (FWT-92D: Far West Technology, Inc. 330-D South Kellogg Goleta, California 93117, USA). The dose was $0.043 \mathrm{MGy}$ at each irradiation.

Penetration depth of the electron beam is one of the important factors for dominating productivity and CFRTP thickness choice to apply for practical use. Based on the density $\left(\rho: \mathrm{kgm}^{-3}\right)$ and irradiation voltage $(V: \mathrm{MeV})$, the EB-irradiation depth $\left(D_{\mathrm{p}}: \mathrm{m}\right)$ is expressed by the following equation. $^{19)}$

$$
D_{\mathrm{p}}=66.7 V^{5 / 3} / \rho
$$

The surface electrical potential $(0.13 \mathrm{MeV})$ is estimated from the electrical potential $(0.17 \mathrm{MeV})$, the $10 \mu \mathrm{m}$ thickness of the titanium $\left(\rho=4.5 \mathrm{Mgm}^{-3}\right)$ window and the $30 \mathrm{~mm}$ distance between the sample and the window in the nitrogen gas atmosphere $\left(\rho=1.1 \mathrm{kgm}^{-3}\right)$. Since the measured density of the CFRTP sample is $1.6 \mathrm{Mgm}^{-3}$, the EB-irradiation depth estimated from eq. (5) is $1.4 \times 10^{-4} \mathrm{~m}(0.14 \mathrm{~mm})$, when the densities $(\rho)$ are $1.8 \mathrm{Mgm}^{-3}$ for carbon fiber and $1.3 \mathrm{Mgm}^{-3}$ for PEEK, respectively. The volume fraction of carbon fiber in PEEK CFRTP was $61 \mathrm{vol} \%$. By using the relation and density, effective depth of EB-irradiation for carbon fiber, PEEK and CFRTP are 0.12, 0.18 and $0.14 \mathrm{~mm}$. Since the effective depth of the sheet electron beam irradiation is $0.28 \mathrm{~mm}$ in the CFRTP, the irradiated depth from each sample surface is $56 \%$ of the CFRTP sample thickness of $0.50 \mathrm{~mm}$.

On the other hand, the HLEBI depth $\left(D_{\mathrm{p}}: \mathrm{m}\right)$, related to the mass thickness $\left(l_{0}: \mathrm{gm}^{-2}\right)$ and irradiation voltage $(E: \mathrm{MeV})$, is also expressed by the following equation suggested by Libby. ${ }^{20)}$

$$
l_{0}=E^{5 / 3} / 150
$$

The estimated mass thickness is $0.35 \mathrm{kgm}^{-2}$, when initial irradiation voltage is $0.17 \mathrm{MeV}$. Since the mass thickness values of Ti foil $\left(l_{0}=18 \mathrm{gm}^{-2}\right)$ and $\mathrm{N}_{2}$ gas $\left(l_{0}=1.5 \mathrm{gm}^{-2}\right)$ reduce the EB-irradiation depth, the mass thickness of CFRTP sample is $0.33 \mathrm{gm}^{-2}$. In addition, the irradiation voltage on the sample surface is expressed by the following equation.

$$
E=\left(150 l_{0}\right)^{3 / 5}
$$


Namely, the EB-irradiation depth of CFRTP is obtained by assumptions of Christenhusz and Reimer (see eq. (6)), ${ }^{19)}$ and Libby. ${ }^{20)}$ Estimated penetration depth of EB-irradiation for carbon fiber, PEEK and CFRTP are 0.12, 0.18 and $0.14 \mathrm{~mm}$ by using the assumption of Christenhusz and Reimer (see eq. (6)), ${ }^{19)}$ and are $0.18,0.26$ and $0.21 \mathrm{~mm}$ by using the assumption of and Libby, ${ }^{20)}$ respectively.

Although the irradiated depth estimated is from 0.14 to $0.21 \mathrm{~mm}$ on both side surfaces of composite sheet with $0.50 \mathrm{~mm}$ thickness, it is expected that the HLEBI improves the flexural modulus of CFRTP.

\subsection{Evaluation of dangling bonds}

To obtain more precise information on atomic-scale structural changes in the glass, the density of the dangling bonds was measured by means of an electron spin resonance spectrometer (ESR, JES-FA200, JEOL Ltd. Tokyo). ${ }^{10,21)}$ The microwave frequency range used in the ESR analysis was the $\mathrm{X}$-band at $9.5 \pm 0.050 \mathrm{GHz}$ with a field modulation of $0.10 \mathrm{MHz}$. The microwave power was $1.0 \mathrm{~mW}$. The magnetic field was varied from 0.32 to $0.33 \mathrm{~T}$. The spin density was calculated by using the $\mathrm{Mn}^{2+}$ standard sample. Only ESR spectra are given, not spin densities. Based on the standard calibration material [4-hydroxy-2,2,6,6-tetra-methylpiperidine-1-oxyl (TEMPOL, 089-04191, Wako Pure Chemical Industries Ltd., Tokyo)] and $\mathrm{Mn}^{2+}$ in the $\mathrm{MnO}$, the density of dangling bonds is estimated by double integration of the intensity of the ESR signal. ${ }^{21)}$

\section{Results}

\subsection{Effects of HLEBI on stress-strain curve}

Figure 2 shows bending stress-bending strain curves of CFRTP (CF/PEEK) with and without HLEBI. Although the irradiated depth estimated is from 0.14 to $0.21 \mathrm{~mm}$ on both side surfaces, effects of HLEBI on bending stress-bending strain curves of CFRTP have been obtained. HLEBI with the small dose of $0.30 \mathrm{MGy}$ to the CFRTP apparently raises the slope $(\mathrm{d} \sigma / \mathrm{d} \varepsilon)$ of the bending stress-bending strain curves.

On the other hand, the additional EB irradiation of 0.86 MGy dose reduces the slope.

\subsection{Effects of HLEBI on flexural modulus of CFRTP}

An influence of EB irradiation on $\mathrm{d} \sigma / \mathrm{d} \varepsilon$ has been evaluated. Figure 3 shows changes in slope of stress-strain curve, which is deformation resistivity $(\mathrm{d} \sigma / \mathrm{d} \varepsilon)$, against bending strain $(\varepsilon)$ at each dose. 0.30 MGy-HLEBI remarkably enhances the $\mathrm{d} \sigma / \mathrm{d} \varepsilon$ of CFRTP at each bending strain. On the other hand, additional HLEBI with large dose of $0.86 \mathrm{MGy}$ is apparently reduces the $\mathrm{d} \sigma / \mathrm{d} \varepsilon$ of CFRTP at each bending strain. This phenomenon is similar to the general radiation damage with high voltage and large dose. ${ }^{22}$ )

\section{Discussion}

\subsection{Effects of HLEBI on $(\mathrm{d} \sigma / \mathrm{d} \varepsilon)$}

Evaluating the cumulative probability of flexural modulus $\left(P_{\mathrm{E}}\right)$ is a convenient method of quantitatively analyzing experimental values. $P_{\mathrm{E}}$ is expressed by the following equation, which is a generalized form of the median rank method. ${ }^{23)}$

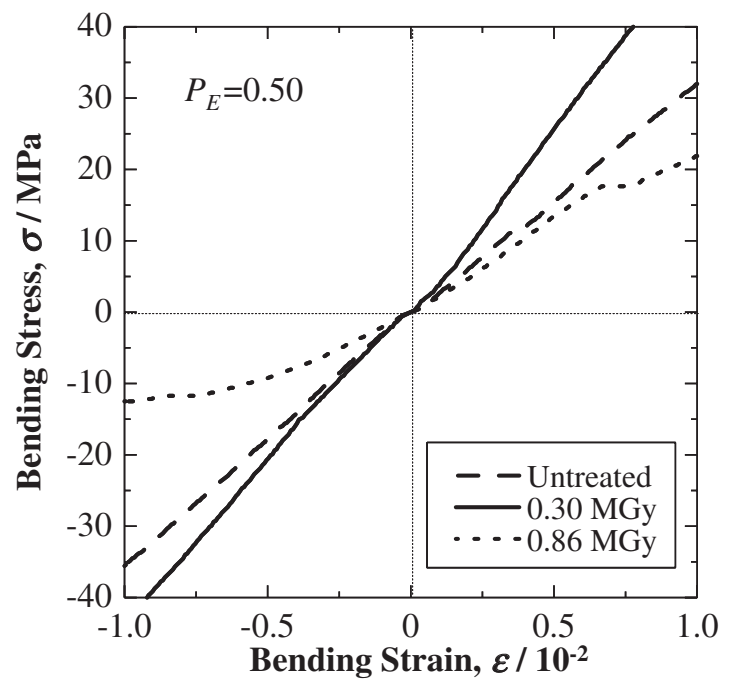

Fig. 2 Bending stress-bending strain curves at $P_{\mathrm{E}}$ of 0.50 for CFRTP irradiated at absorbed doses of 0.30 and $0.86 \mathrm{MGy}$, respectively.

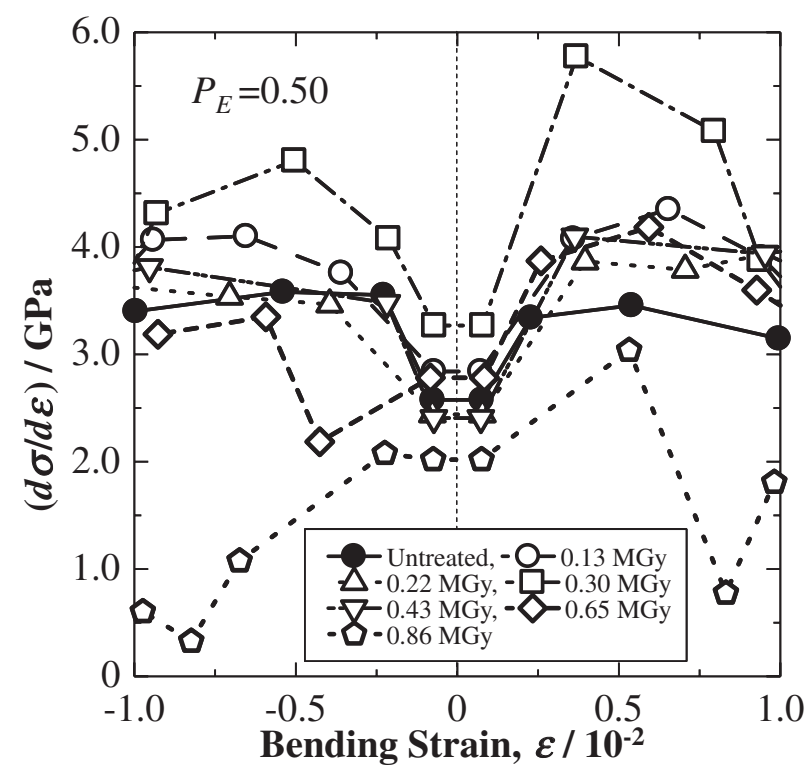

Fig. 3 Relationships between slope $(\mathrm{d} \sigma / \mathrm{d} \varepsilon)(\mathrm{GPa})$ of bending stress-strain curve and bending strain $(\varepsilon)$ of CFRTP irradiated at each absorbed dose of HLEBI.

$$
P_{\mathrm{E}}=(i-0.3) /\left(N_{\mathrm{s}}+0.4\right)
$$

Here $N_{\mathrm{s}}$ and $i$ are the total number of samples $\left(N_{\mathrm{s}}=11\right)$, and the rank order integer of flexural modulus $\left(E_{\mathrm{f}}\right)$ of each sample, respectively, where $i$ is from low to high rank. When the $i$ values are 2, 6, and 10, their corresponding $P_{\mathrm{E}}$ values are $0.15,0.50$ and 0.85 , respectively.

Figure 4 shows changes in $E_{\mathrm{f}}$ of CFRTP against $P_{\mathrm{E}}$ value at each dose of HLEBI. Here, remarkable effects of HLEBI on $E_{\mathrm{f}}$ of CFRTP have been obtained at $P_{\mathrm{E}}$ values from 0.15 to 0.59 , although $E_{\mathrm{f}}$ enhancement cannot be found at the high $P_{\mathrm{E}}$ values higher than 0.68 .

Note the direct irradiation of more than $0.30 \mathrm{MGy}$ remarkably enhances the $E_{\mathrm{f}}$ value of the CFRTP at $P_{\mathrm{E}}$ values from 0.15 to 0.59 .

When $P_{\mathrm{E}}$ is between 0.061 and 0.94 (see Fig. 4), the difference $(3.0 \mathrm{GPa}$ ) between 1.6 and $4.6 \mathrm{GPa}$ before HLEBI 


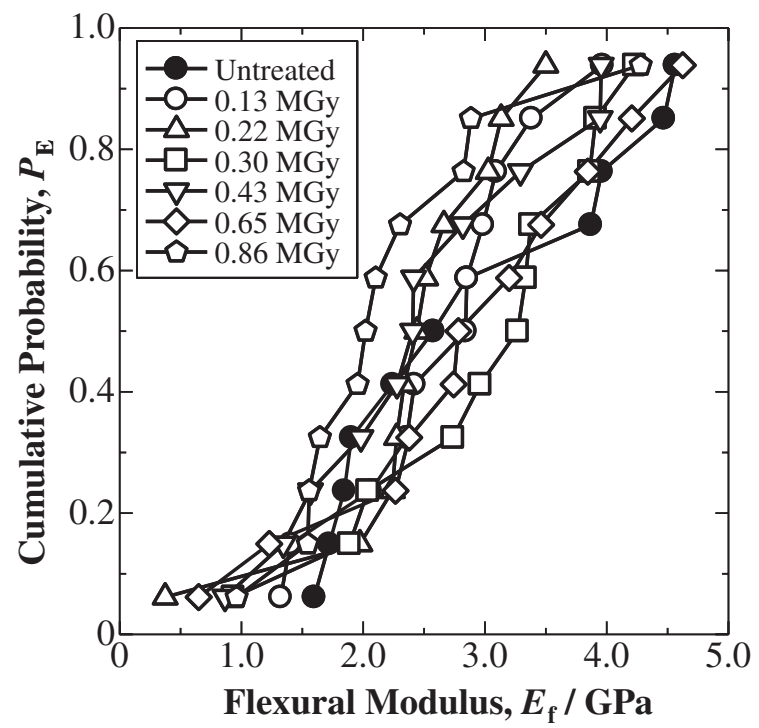

Fig. 4 Relationships between flexural modulus $\left(E_{\mathrm{f}}\right)(\mathrm{GPa})$ of CFRTP irradiated at each absorbed dose of HLEBI and cumulative probability $\left(P_{\mathrm{E}}\right)$.

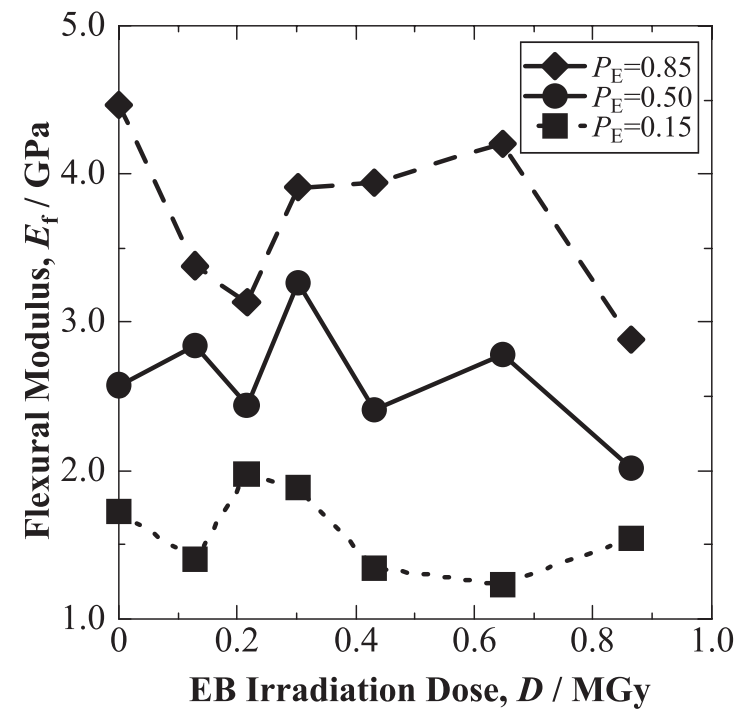

Fig. 5 Changes in flexural modulus $\left(E_{\mathrm{f}}\right)$ at $P_{\mathrm{E}}=0.15,0.50$ and 0.85 of CFRTP plotted against absorbed dose of HLEBI.

is about $10 \%$ higher than that $(2.7 \mathrm{GPa})$ between 1.3 and 4.0 GPa after 0.13 MGy-HLEBI. Consequently, 0.13 MGyHLEBI reduces the experimental data difference from 3.0 GPa before HLEBI to 2.7 GPa after 0.13 MGy-HLEBI, resulting in enhancement of reproducibly of PEEK-CFRTP by HLEBI.

Figure 5 shows changes in $E_{\mathrm{f}}$ value of CFRTP against dose of HLEBI at each $P_{\mathrm{E}}$ value. Additional EB irradiation of $0.86 \mathrm{MGy}$ apparently reduces the $\mathrm{d} \sigma / \mathrm{d} \varepsilon$ values at high and mid $P_{\mathrm{E}}$ of 0.85 and 0.50 , as the common radiation damage. ${ }^{16,22)}$

On the other hand, compared with the sample before irradiation, the irradiation from 0.22 to $0.30 \mathrm{MGy}$ apparently enhances the $E_{\mathrm{f}}$ value of the CFRTP at low $P_{\mathrm{E}}$ value of 0.15 . The irradiation at $0.30 \mathrm{MGy}$ also enhances the $E_{\mathrm{f}}$ value of the CFRTP at mid $P_{\mathrm{E}}$ value of 0.50. 0.30 MGy-HLEBI enhances the $E_{\mathrm{f}}$ value from 2.6 to $3.3 \mathrm{GPa}$ and from 1.7 to $1.9 \mathrm{GPa}$ at

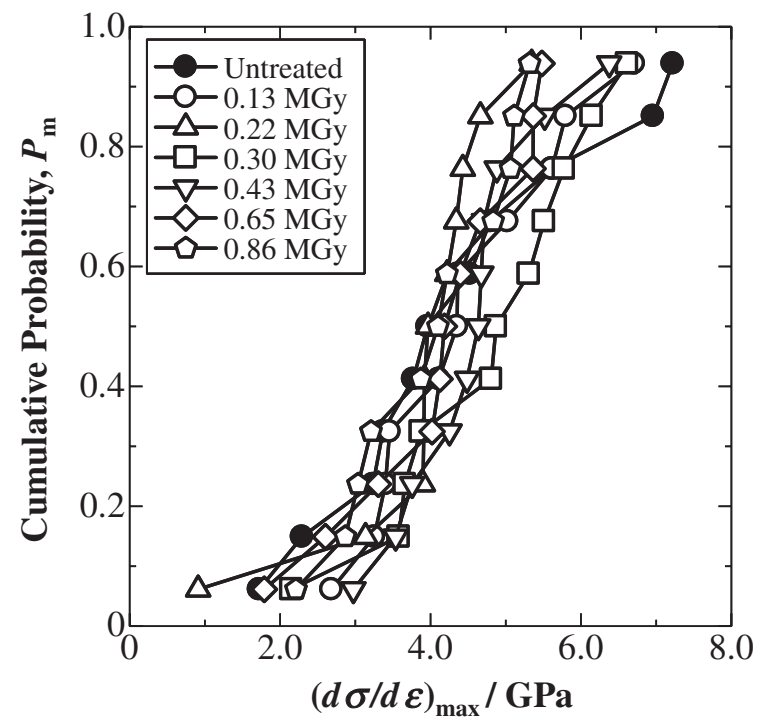

Fig. 6 Relationships between the maximum slope value $\left((\mathrm{d} \sigma / \mathrm{d} \varepsilon)_{\max }\right)$ (GPa) of bending stress-strain curve of CFRTP irradiated at each absorbed dose of HLEBI and cumulative probability of $(\mathrm{d} \sigma / \mathrm{d} \varepsilon)_{\max }\left(P_{\mathrm{m}}\right)$.

mid and low $P_{\mathrm{E}}$ values of 0.50 and 0.15 , respectively. They are about $27.5 \%$ higher than those before irradiation.

Although drops of $E_{\mathrm{f}}$ values are found at each $P_{\mathrm{E}}$ from 0.15 to 0.85 , the data distribution becomes small for CFRTP irradiated at $0.22 \mathrm{MGy}$. Furthermore, the highest $E_{\mathrm{f}}$ value of more than $2.0 \mathrm{GPa}$ is found at low $P_{\mathrm{E}}$ of 0.15 .

When $P_{\mathrm{E}}$ is between 0.15 and 0.85 (see Fig. 5), the difference $(2.7 \mathrm{GPa}$ ) between 1.7 and $4.4 \mathrm{GPa}$ before HLEBI is about two times higher than that $(1.1 \mathrm{GPa})$ between 2.0 and 3.1 GPa after 0.22 MGy-HLEBI. Consequently, 0.22 MGyHLEBI reduces the experimental data difference from 2.7 GPa before HLEBI to $1.1 \mathrm{GPa}$ after $0.22 \mathrm{MGy}-\mathrm{HLEBI}$, resulting in enhancement of reproducibly of PEEK-CFRTP by HLEBI.

As shown in Figs. 4 and 5, 0.22 MGy-HLEBI enhances the $E_{\mathrm{f}}$ at low $P_{\mathrm{E}}$ of 0.15 as well as enhancement of reproducibly of PEEK-CFRTP.

\subsection{Effects of HLEBI on $(\mathrm{d} \sigma / \mathrm{d} \varepsilon)_{\max }$}

The maximum slope value $\left((\mathrm{d} \sigma / \mathrm{d} \varepsilon)_{\max }\right)$ of the bending stress-strain curve of each CFRTP sample is the maximum $\mathrm{d} \sigma / \mathrm{d} \varepsilon$ value in Fig. 3. Although all $(\mathrm{d} \sigma / \mathrm{d} \varepsilon)_{\max }$ values are not found in the initial slope at initial strain of zero in Fig. 3, they are obtained at the elastic deformed strain $(\varepsilon)$ from \pm 0.25 to \pm 0.75 , respectively. Figure 6 shows changes in $(\mathrm{d} \sigma / \mathrm{d} \varepsilon)_{\max }$ of CFRTP at each dose of HLEBI against cumulative probability of $(\mathrm{d} \sigma / \mathrm{d} \varepsilon)_{\max }\left(P_{\mathrm{m}}\right)$. Remarkable effects of HLEBI on $(\mathrm{d} \sigma / \mathrm{d} \varepsilon)_{\max }$ value of CFRTP have been obtained at $P_{\mathrm{m}}$ value from 0.06 to 0.68 . Although the $(\mathrm{d} \sigma / \mathrm{d} \varepsilon)_{\max }$ enhancement cannot be found at high $P_{\mathrm{m}}$ of more than 0.76 , the irradiation mostly enhances the $(\mathrm{d} \sigma / \mathrm{d} \varepsilon)_{\max }$ values at low $P_{\mathrm{m}}$ values of less than 0.50 .

When $P_{\mathrm{m}}$ is between 0.061 and 0.94 (see Fig. 6), the difference (5.5 GPa) between 1.7 and 7.2 GPa before HLEBI is about $38 \%$ higher than that $(4.0 \mathrm{GPa})$ between 2.7 and 6.7 GPa after 0.13 MGy-HLEBI. Consequently, 0.13 MGyHLEBI reduces the experimental data difference from 5.5 GPa before HLEBI to 4.0 GPa after 0.13 MGy-HLEBI, 


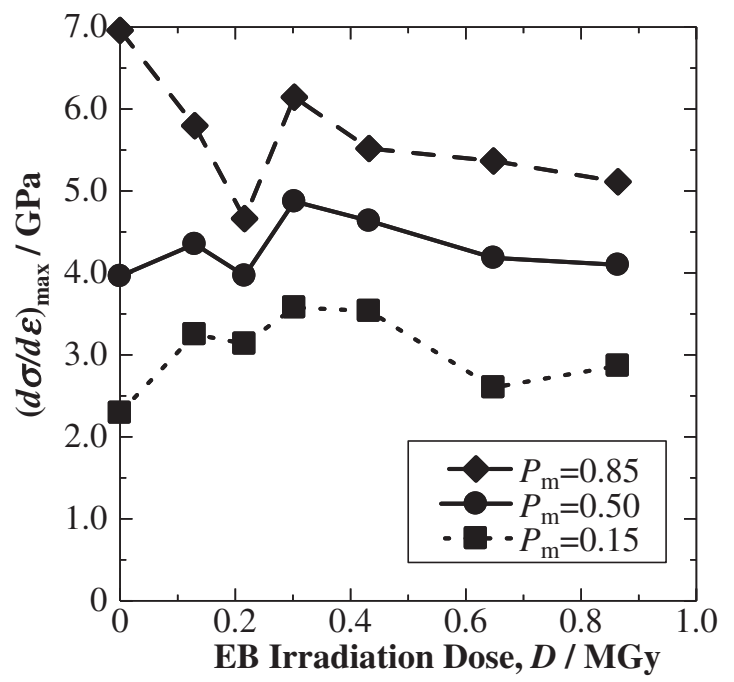

Fig. 7 Changes in the maximum slope value $\left((\mathrm{d} \sigma / \mathrm{d} \varepsilon)_{\max }\right)(\mathrm{GPa})$ of bending stress-strain curve at $P_{\mathrm{m}}=0.15,0.50$ and 0.85 of CFRTP plotted against the absorbed dose of HLEBI.

resulting in enhancement of reproducibly of $(\mathrm{d} \sigma / \mathrm{d} \varepsilon)_{\max }$ of PEEK-CFRTP by the HLEBI.

Figure 7 shows changes in $(\mathrm{d} \sigma / \mathrm{d} \varepsilon)_{\max }$ value of CFRTP against dose of HLEBI at each $P_{\mathrm{m}}$ value. Although additional EB irradiation of more than $0.43 \mathrm{MGy}$ gradually reduces the $(\mathrm{d} \sigma / \mathrm{d} \varepsilon)_{\max }$ values at each $P_{\mathrm{m}}$, as the common radiation damage, $(\mathrm{d} \sigma / \mathrm{d} \varepsilon)_{\max }$ values of the CFRTP irradiated at each dose from 0.13 to $0.86 \mathrm{MGy}$ is apparently higher than that before treatment at both low and mid $P_{\mathrm{m}}$ values of 0.15 and 0.50 .

Furthermore, 0.30 MGy-HLEBI enhances the $(\mathrm{d} \sigma / \mathrm{d} \varepsilon)_{\max }$ value from 4.0 to $4.9 \mathrm{GPa}$. The $(\mathrm{d} \sigma / \mathrm{d} \varepsilon)_{\max }$ value of CFRTP irradiated at $0.30 \mathrm{MGy}$ is about $23 \%$ higher than that without irradiation at mid $P_{\mathrm{m}}$ value of 0.50 .

$0.30 \mathrm{MGy}-H L E B I$ enhances the $(\mathrm{d} \sigma / \mathrm{d} \varepsilon)_{\max }$ value from 2.3 to $3.6 \mathrm{GPa}$ at low $P_{\mathrm{m}}$ value of 0.15 . The $(\mathrm{d} \sigma / \mathrm{d} \varepsilon)_{\max }$ value of CFRTP irradiated at $0.30 \mathrm{MGy}$ is about $56 \%$ higher than that without irradiation at mid $P_{\mathrm{m}}$ value of 0.15 .

Although the drop of $(\mathrm{d} \sigma / \mathrm{d} \varepsilon)_{\max }$ value is remarkably found at $P_{\mathrm{m}}$ of 0.85 , the data distribution becomes small for CFRTP irradiated at $0.22 \mathrm{MGy}$. Although both $0.65 \mathrm{MGy}$-irradiation and high $P_{\mathrm{m}}$ values of 0.85 cannot improve the $(\mathrm{d} \sigma / \mathrm{d} \varepsilon)_{\max }$, $0.30 \mathrm{MGy}$-irradiation enhances the $(\mathrm{d} \sigma / \mathrm{d} \varepsilon)_{\max }$ values.

When $P_{\mathrm{m}}$ is between 0.15 and 0.85 (see Fig. 7), the difference (4.7 GPa) between 2.3 and 7.0 GPa before HLEBI is about three times higher than that $(1.6 \mathrm{GPa})$ between 4.7 and $3.1 \mathrm{GPa}$ after $0.22 \mathrm{MGy}-\mathrm{HLEBI}$. Consequently, 0.22 MGy-HLEBI reduces the experimental data difference from 4.7 GPa before HLEBI to 1.6 GPa after 0.22 MGy-HLEBI, resulting in enhancement of reproducibly of $(\mathrm{d} \sigma / \mathrm{d} \varepsilon)_{\max }$ of PEEK-CFRTP by HLEBI.

As shown in Figs. 6 and 7, 0.22 MGy-HLEBI enhances the $(\mathrm{d} \sigma / \mathrm{d} \varepsilon)_{\max }$ value at low $P_{\mathrm{m}}$ of 0.15 as well as its enhancement of reproducibly of $(\mathrm{d} \sigma / \mathrm{d} \varepsilon)_{\max }$ of PEEK-CFRTP.

4.3 Effects of dangling bonds induced by HLEBI on $(\mathrm{d} \sigma / \mathrm{d} \varepsilon)_{\max }$ improvement of CFRTP constructed with carbon fiber, PEEK and their interface

Improvement of the $(\mathrm{d} \sigma / \mathrm{d} \varepsilon)_{\max }$ of CFRTP by HLEBI probably depends on strengthening carbon fiber, ductility enhancement of polymer matrix, and enhancement of interfacial friction.

From the conventional X-ray diffraction patterns of the carbon fiber before and after the EB irradiation, remarkable differences cannot be observed. On the other hand, EB irradiation in fact produces detectable dangling bonds. ${ }^{9,10,14)}$ To discuss the influences of electron beam irradiation on the $(\mathrm{d} \sigma / \mathrm{d} \varepsilon)_{\max }$, ESR signals related to dangling bonds have been observed.

Dangling bonds spontaneously exist in carbon fiber before irradiation. The densities of dangling bonds of the carbon fibers before and after $0.30 \mathrm{MGy}$-irradiation are $1.2 \times 10^{17}$ and $4.7 \times 10^{16}$ spins $\mathrm{mm}^{-3}$, respectively. Although additional irradiation generally enhances the density and induces the radiation damage, $0.30 \mathrm{MGy}-\mathrm{HLEBI}$ decreases the density of dangling bonds. Annihilation of dangling bonds of carbon fiber has often enhanced the tensile fracture stress and fracture strain of bending tests. ${ }^{9,10,14)}$

HLEBI annihilates dangling bonds in the hexagonal atomic structure of graphite,,${ }^{9,10}$ it often enhances the elasticity, resulting in strengthening of the carbon fiber. ${ }^{8,9)}$ In addition, HLEBI often enhances the strengthening of the polymer matrix, although additional irradiation generally induces the radiation damage. ${ }^{5)}$

The ESR signals of PEEK with and without EB irradiation are observed for the irradiated and untreated PEEK corresponding to dangling bonds. ${ }^{17}$ The densities of dangling bonds of PEEK samples before and after $0.30 \mathrm{MGy}$ irradiation are $1.5 \times 10^{12}$ and $5.0 \times 10^{12}$ spins $\mathrm{mm}^{-3}$, respectively. The electron beam irradiation at $0.30 \mathrm{MGy}$ increases the intensity of ESR signal, which exhibits to generate the dangling bonds in PEEK.

When HLEBI cuts the weak chemical bonds of PEEK, the repulsive force between terminated atoms with dangling bonds occurs, resulting in generating volume expansion at dangling bonds. The expansion induced by HLEBI generates the compressive stress to enhance the elasticity indicated by both $E_{\mathrm{f}}$ and $(\mathrm{d} \sigma / \mathrm{d} \varepsilon)_{\max }$ values in the PEEK matrix.

While the compressive stress induced by HLEBI also enhances the frictional force at the carbon fiber/PEEK interface, it prevents carbon fiber pull-out. Based on both effects of compressive stress, HLEBI enhances both $E_{\mathrm{f}}$ and $(\mathrm{d} \sigma / \mathrm{d} \varepsilon)_{\max }$ values of CFRTP. The interfacial friction force, as well as the strengthening of both carbon fiber and polyetheretherketone probably contributes the HLEBI effects to enhance both $E_{\mathrm{f}}$ and $(\mathrm{d} \sigma / \mathrm{d} \varepsilon)_{\max }$ values of CFRTP.

On the other hand, additional EB irradiation of more than $0.86 \mathrm{MGy}$ apparently decreases the $(\mathrm{d} \sigma / \mathrm{d} \varepsilon)_{\max }$ at all $P_{\mathrm{E}}$ values, as shown in Figs. 5 and 7. Since the additional irradiation easily breaks the chemical bonds of PEEK polymer and carbon fiber, it probably generates many relaxation sites, resulting in softening. The decay of $(\mathrm{d} \sigma / \mathrm{d} \varepsilon)_{\max }$ of CFRTP irradiated at $0.86 \mathrm{MGy}$ can be explained by the excess formation of dangling bonds.

\subsection{Penetration depth of HLEBI into PEEK}

In order to confirm the penetration depth $\left(D_{\mathrm{p}}\right), 0.28 \mathrm{~mm}$ thickness PEEK sheet laminated by eleven PEEK films with $25 \mu \mathrm{m}$ thickness has been irradiated. Dangling bond density 


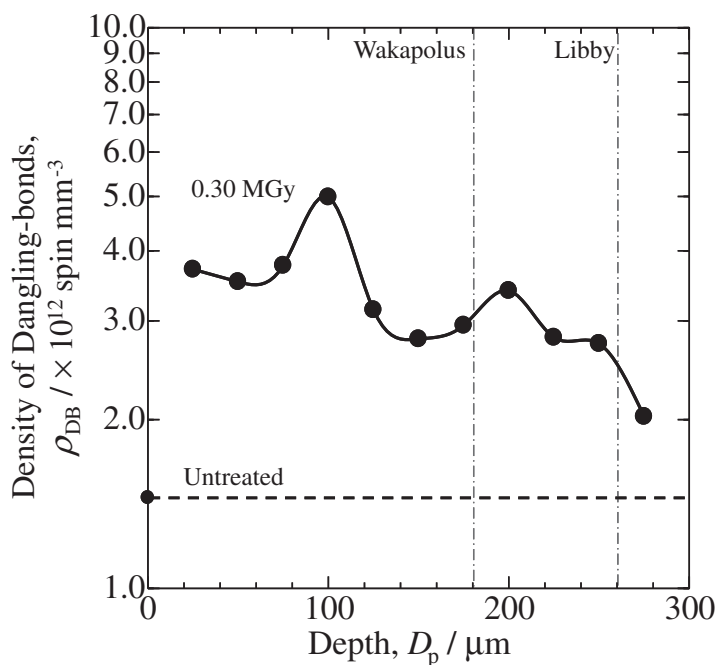

Fig. 8 Changes in dangling bonds density of PEEK irradiated by $0.30 \mathrm{MGy}$ against penetration depth $\left(D_{\mathrm{p}}\right)$ of HLEBI, together with that before irradiation (broken line).

has been evaluated by electron spin resonance (ESR) spectra. Figure 8 shows changes in dangling bond density of PEEK irradiated by $0.30 \mathrm{MGy}$ against $D_{\mathrm{p}}$, together with that before irradiation (broken line). Although the dangling bond density of PEEK before irradiation is $1.5 \times 10^{12}$ spins $\mathrm{mm}^{-3}$, the high density of dangling bonds of from $2.0 \times 10^{12}$ to $5.0 \times$ $10^{12}$ spins $\mathrm{mm}^{-3}$ is observed from the surface to $0.25 \mathrm{~mm}$ $D_{\mathrm{p}}$ of PEEK irradiated at the 0.30 MGy HLEBI dose. Consequently, the experimental drastic reduction zone of PEEK is $0.03 \mathrm{~mm}$ from 0.25 to $0.28 \mathrm{~mm}-D_{\mathrm{p}}$.

The estimated penetration depth of irradiated PEEK by using the assumptions of Libby ${ }^{20)}\left(0.26 \mathrm{~mm}-D_{\mathrm{p}}\right)$ is mostly agrees with the experimental value of $0.25 \mathrm{~mm}-D_{\mathrm{p}}$. Based on the Libby ${ }^{20)}$ assumption, the estimated penetration depth of EB-irradiation for CFRTP is probably $0.21 \mathrm{~mm}$. When the experimental drastic reduction middle zone of PEEK $(0.03 \mathrm{~mm})$ assumes to be approximately equal to that of CFRTP, its sample with $0.50 \mathrm{~mm}$ thickness is probably constructed with the irradiation zone outside near surface, middle zone and irradiation free zone inside. Their thickness values are $0.42,0.06$ and $0.02 \mathrm{~mm}$.

Since the irradiation free zone retains the inside part with small bending stress near neutral point of bending deformation, its influence on $\mathrm{d} \sigma / \mathrm{d} \varepsilon$ of CFRTP is negligible small. Therefore, we conclude that the HLEBI apparently improves flexural modulus of CFRTP.

\section{Conclusion}

In summary, effects of homogeneous low voltage electron beam irradiation (HLEBI) on flexural modulus of carbon fiber reinforced thermoplastic polyetheretherketone (CFRTP) have been found, although the penetration depth estimated is from 0.14 to $0.21 \mathrm{~mm}$ on both side surfaces of $0.50 \mathrm{~mm}$ thick composite sheet.

(1) $0.30 \mathrm{MGy}-$ HLEBI remarkably enhances the $\mathrm{d} \sigma / \mathrm{d} \varepsilon$ of CFRTP at each bending strain. On the other hand, additional HLEBI with large dose of $0.86 \mathrm{MGy}$ is apparently reduces the $\mathrm{d} \sigma / \mathrm{d} \varepsilon$ of CFRTP at each bending strain.
(2) The flexural modulus $\left(E_{\mathrm{f}}\right)$ at its middle cumulative probability $\left(P_{\mathrm{E}}\right)$ of 0.50 for CFRTP irradiated at $0.30 \mathrm{MGy}$ $\left(\mathrm{kJg}^{-1}\right)$ is $3.3 \mathrm{GPa}$, which is $27 \%$ higher than that $(2.6 \mathrm{GPa})$ for CFRTP before irradiation. Thus, the HLEBI enhances the stiffness.

(3) HLEBI enhances the maximum slope value ((d $\sigma /$ $\left.\mathrm{d} \varepsilon)_{\max }\right)$ of bending stress-strain curve. The $\left.(\mathrm{d} \sigma / \mathrm{d} \varepsilon)_{\max }\right)$ at its middle cumulative probability $\left(P_{\mathrm{m}}=0.50\right)$ was more than 4.9 $\mathrm{GPa}$ for CFRTP irradiated at $0.30 \mathrm{MGy}$.

(4) The interfacial friction force, as well as the strengthening of both carbon fiber and polyetheretherketone (PEEK), probably contributes to the HLEBI effects to enhance both $E_{\mathrm{f}}$ and $(\mathrm{d} \sigma / \mathrm{d} \varepsilon)_{\max }$ in the CFRTP.

(5) $0.22 \mathrm{MGy}-\mathrm{HLEBI}$ enhances both $E_{\mathrm{f}}$ and $(\mathrm{d} \sigma / \mathrm{d} \varepsilon)_{\max }$ values at low $P_{\mathrm{E}}$ of 0.15 as well as enhancing the experimental reproducibly of PEEK-CFRTP results.

\section{Acknowledgement}

Authors would like to thank Prof. Michael C. Faudree and Dr. Keisuke Iwata of Tokai University for their useful helps. This work is partly supported by Minister of Industry and ENSM-SE in France.

\section{REFERENCES}

1) D. K. Thomas: Plastics Rubber Int. 8 (1983) 53-57.

2) M. B. Dowell: Plastics Eng. 33 (1977) 31-32.

3) S. Egusa: J. Mater. Sci. 23 (1988) 2753-2760.

4) T. Takahashi, T. Morishita and Y. Nishi: J. Jpn. Inst. Metals 69 (1988) 2753-2760.

5) A. Mizutani and Y. Nishi: Mater. Trans. 44 (2003) 1857-1860.

6) K. Oguri, N. Iwataka, A. Tonegawa, Y. Hirose, K. Takayama and Y. Nishi: J. Mater. Res. 16 (2001) 553-557.

7) K. Oguri, K. Fujita, M. Takahashi, Y. Omori, A. Tonegawa, N. Honda, M. Ochi, K. Takayama and Y. Nishi: J. Mater. Res. 13 (1998) 33683371.

8) K. Oguri, N. Iwatani, H. Izumi, A. Tonegawa, K. Takayama and Y. Nishi: Proc. 2nd Japan-France Seminar on Intelligent Materials and Structures, (University of Louis Pasteur Strasbourg, France) (1998) pp. 142-144.

9) Y. Nishi, T. Toriyama, K. Oguri, A. Tonegawa and K. Takayama: J. Mater. Res. 16 (2001) 1632-1635.

10) Y. Nishi, A. Mizutani, A. Kimura, T. Toriyama, K. Oguri and A. Tonegawa: J. Mater. Sci. 38 (2003) 89-92.

11) Y. Nishi, K. Inoue and M. Salvia: Mater. Trans. 47 (2006) 2846-2851.

12) H. Kosuda and K. Nakama: Kagaku Keizai 28 (1981) 28-34.

13) H. Sato, K. Iwata, A. Tonegawa and Y. Nishi: J. Jpn. Inst. Metals 72 (2008) 526-531.

14) Y. Nishi, A. Mizutani and N. Uchida: J. Thermoplastic Compos. Mater. 17 (2004) 289-302.

15) M. Makihara: Plastics 53 (2002) 119-122.

16) K. Komai, K. Minoshima and K. Tanaka: Trans. Jpn. Soc. Mech. Eng. A 64 (1998) 2300-2307.

17) Y. Nishi, H. Takei, K. Takata, K. Iwata, M. Salvia and A. Vautrin: Mater. Trans. 50 (2009) 2826-2832.

18) Japanese Industrial Standards Committee: JIS K7074 (1998).

19) R. Christenhusz and L. Reimer: Z. Angew. Phys. 23 (1967) 396-404.

20) W. F. Libby: Anal. Chem. 19 (1947) 2-6.

21) Kyushu Branch, The Japan society for Analytical Chemistry: Introduction to instrumental analysis, (Nankodo co., Ltd. 1996) pp. 214229.

22) T. Sasuga, M. Hagiwara, T. Odajima, H. Sakai, T. Nakakura and M. Masutani: JAERI-M reports, (JAERI-M 87-048, 1987).

23) T. Nishida and E. Yasuda: Evaluation of dynamic properties of ceramics (in Japanese: Ceramics no rikigaku tokusei hyouka) (Nikkan Kogyou Shimbun Sha, Tokyo, 1986) pp. 50-51. 